
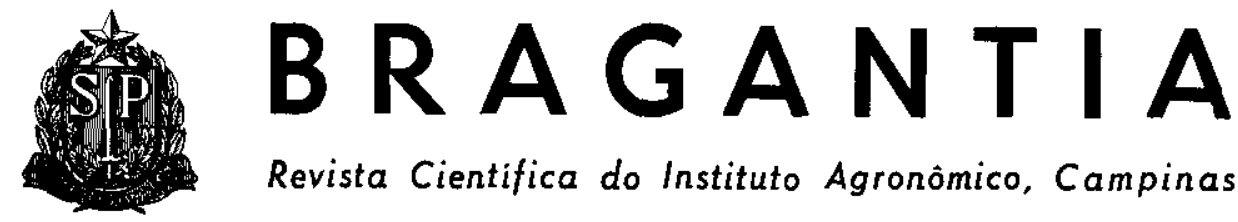

Revista Cientifica do Instituto Agronômico, Campinas

\title{
RESTOS VEGETAIS DA CULTURA DA MAMONA COMO MATERIA-PRIMA PARA CELULOSE (')
}

Anfsio Azzini (2), Antonio Luiz de Barros Salgado (2), Seção de Plantas Fibrosas, angelo Savy Filho, Seção de Oleaginosas, e Nicolad Victorio Banzatro, Diretor da Divisāo de Biologia Fitotéenica, Instituto Agronômico

\section{RESUMO}

Restos vegetais da cultura da mamona foram estudados visando ao seu aproveitamento para obtençāo de celulose para papel. Os resultados obtidos mostraram que a cultura da mamona fornece grande quantidade de resíduo agrícola fibroso de baixa densidade básica e com bom rendimento de conversão em celulose. Suas fibras liberianas e lenhosas podem ser consideradas, respectivamente, como longas e curtas, comparando-as com as fibras de pinus e eucalipto.

\section{INTRODUÇÃO}

A cultura da mamona em nosso País é de grande importância, não só por ser o Brasil o maior produtor mundial dessa oleaginosa, mas, principalmente, pelo valor industrial do seu óleo, que, em decorrência da atual crise de petróleo, apresenta novas perspectivas de utilização nas indústrias química, têxtil, eletrônica, mecânica e automotiva. O óleo de mamona tem sido empregado na indústria de lubrificantes, revestimentos protetores, vernizes e tintas látex, ceras impermeabilizantes de couros $\mathrm{e}$ na fabricação de náilon $6-10$, do náilon 11 (Rilsan) e outros (2).

O resíduo agrícola fibroso proveniente da cultura da mamona, após a colheita das sementes, poderá ser empregado como fonte adicional de fibras na indústria de celulose e papel, que está vivendo uma situação de "deficit" de matéria-prima vegetal.

O objetivo desse trabalho foi determinar características tecnológicas de três cultivares de mamona, visando à obtenção de oelulose para papel.

\section{MATERIAL E METODOS}

Os materiais fibrosos empregados foram os restos vegetais (parte aérea das plantas, com exceção das folhas) da cultura de três cultivares de mamona (Guarani, Borracha e Preta) provenientes de um experi-

(1) Recebido para publicação a 24 de setembrón de 1980.

(') Com bolsa de suplementaçāo do CNPq. 
Vol. 40, Art. n. ${ }^{\circ} 11$

mento conduzido pela Seção de Oleaginosas, no Centro Experimental de Campinas, no ano agrícola 1978/79.

Para cada cultivar, foram coletadas cinco plantas típicas e homogêneas, determinando-se a altura, diâmetro basal e peso das plantas. A quantidade dos restos vegetais da cultura foi calculada, levando-se em consideração o peso médio das plantas e o número de plantas por unidade de área no experimento.

A densidade básica dos caules de mamona foi determinada pelo método ABCP-M 14/70 (1). Para cada cultivar, foram utilizadas dez amostras retiradas da região basal dos caules.

A quantidade de líber ou casca foi calculada pela relação percentual entre os pesos secos ao ar do líber e do conjunto líber-lenho. $\mathrm{O}$ rendimento em celulose nesse conjunto foi determinado de acordo com NIESCHLAG et alii (6), após a maceração das amostras em uma solução contendo $50 \%$ de ácido acético glacial, $30 \%$ de água oxigenada a 130 volumes e $20 \%$ de água destilada.

As dimensões das fibras liberianas e lenhosas foram determinadas com auxílio de microscópio provido de ocular micrométrica especial, com filamento móvel, utilizando-se as amostras maceradas.

A partir das dimensōes fundamentais (comprimento, largura, diâmetro do lúmen e espessura da parede celular), foram calculadas as seguintes relações:

- Coeficiente de flexibilidade: relação percentual entre $o$ diâmetro do lúmen e a largura da fibra.

- Fração-parede: relação percentual entre a espessura da parede celular e o raio da fibra.

- Indice de enfeltramento: relação entre o comprimento e a largura da fibra.

- Indice de Runkel: relação entre duas vezes a espessura da parede celular e o diâmetro do lúmen.

\section{RESULTADOS E DISCUSSÃO}

Os dados do quadro 1 mostram que houve variação entre as dimensões e peso das plantas de mamona. O cultivar Guarani, de menor porte e plantado em menor espaçamento, forneceu maior quantidade de restos de cultura por unidade de área; comparada com a produção do Eucaliptus grandis $(24,4 \mathrm{t} / \mathrm{ha} / \mathrm{ano})(5)$, evidencia a grande potencialidade de utilização desse material pela indústria de celulose e papel.

QUADRO 1 - Altura, diâmetro basal e peso das plantas e quantidada dos restos da cultura em três cultivares de mamona. Médias de cinco repetiçōes

\begin{tabular}{lcccc} 
Cultivar & $\begin{array}{c}\text { Altura da } \\
\text { planta }\end{array}$ & $\begin{array}{c}\text { Diâmetro } \\
\text { basal }\end{array}$ & $\begin{array}{c}\text { Peso da } \\
\text { planta }\end{array}$ & $\begin{array}{c}\text { Quantidade dos } \\
\text { restos da cultura }\end{array}$ \\
\hline Guarani & $\mathrm{m}$ & $\mathrm{cm}$ & $\mathrm{kg}$ & $\mathrm{t} / \mathrm{ha}$ \\
Borracha & 2,08 & 398 & 1,84 & 24,53 \\
Preta & 3,02 & 6,38 & 6,22 & 20,73 \\
\hline
\end{tabular}


Conforme se verifica no quadro 2 , a densidade básica e a porcentagem de líber dos caules variaram entre os cultivares estudados. $\mathrm{O}$ 'Guarani', com menor densidade básica do caule, apresentou maior porcentagem de líber. Quanto ao rendimento em celulose, não houve diferença entre os cultivares.

O caule de mamona apresenta menor densidade básica que as madeiras de eucalipto $\left(0,530 \mathrm{~g} / \mathrm{cm}^{3}\right)$ e pinus $\left(0,412 \mathrm{~g} / \mathrm{cm}^{3}\right)(3)$, que são as matérias-primas tradicionalmente utilizadas em nosso País para produção de celulose e papel.

A densidade do material fibroso empregado na produção de celulose influi nas características físico-mecânicas do papel produzido. BARRICHELO \& BRITO (2) salientaram que a madeira de eucalipto, com densidade elevada, normalmente produz um tipo de papel de alta resistência ao rasgo e baixa resistência à tração, ao arrebentamento e à dobragem. A baixa densidade do caule de mamona deve influir negativamente no rendimento nominal do digestor, diminuindo sud capacidade de produção.

Quanto às dimensões das fibras liberianas e lenhosas (quadro 3 e figuras 3,4 e 5 ), elas se mostraram semelhantes nos três cultivares estudados. Deve-se ressaltar, entretanto, que as fibras liberianas são bem mais longas que as lenhosas. Em relação ao comprimento das fibras de Pinus oocarpa $(3,8 \mathrm{~mm})$ (3) e Eucaliptus saligna $(0,94 \mathrm{~mm})(\mathbf{4})$, as fibras liberianas da mamona são extremamente longas, enquanto as lenhosas, de comprimento semelhante às fibras de eucalipto, são curtas.

As figuras 1 e 2 ilustram a distribuição percentual das fibras em diversas classes de comprimento.

Nas figuras 3,4 e 5 aparecem as fotomicrografias das fibras liberianas e lenhosas dos cultivares estudados.

QUADRO 2 - Densidade básica, porcentagem de líber e rendimento macerado em restos vegetais de três cultivares de mamona. Médias de dez repetiçōes

\begin{tabular}{lccc}
\hline Cultivar & $\begin{array}{c}\text { Densidade } \\
\text { básica }\end{array}$ & Liber & $\begin{array}{c}\text { Rendimento } \\
\text { macerado }\end{array}$ \\
\hline Borracha & $\begin{array}{c}\mathrm{g} / \mathrm{cm}^{3} \\
0,241 \mathrm{a}\left(^{1}\right)\end{array}$ & $\begin{array}{c}\% \\
\text { Preta }\end{array}$ & $\mathbf{1 5 , 5 2 \mathrm { ab }}$ \\
Guarani & $0,230 \mathrm{~b}$ & $12,96 \mathrm{~b}$ & 49.17 \\
\hline F & $0,156 \mathrm{c}$ & $17,49 \mathrm{a}$ & 42.34 \\
Tukey $(5 \%)$ & $\mathbf{2 8 3 , 7 8 * *}$ & $\mathbf{7 , 8 3 * *}$ & 47,05 \\
C.V. $(\%)$ & 0,009 & 3.05 & $\mathrm{~ns}$ \\
\hline
\end{tabular}

(1) Letras não comuns indicam diferenças significativas ao nível de $1 \%$.

(**) Significativo ao nivel de $1 \%$.

$\mathrm{ns}=$ Não significativo. 




Figura 1. - Distribuição percentual das fibras liberianas de três cultivates da mamona em diversas classes de comprimento: Guarani (G). Preta (P) e Borracha (B).

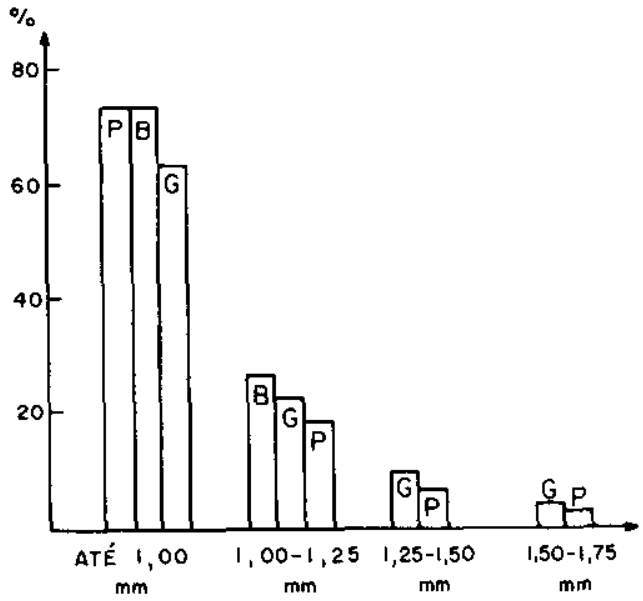

Figura 2. - Distribuição percentual das fibras lenhosas de ttês cultivares de mamona en diversas classes de comptimento:

Preta (P). Borracha (B) e Guarani (G). 
Azzini et alii

형 용

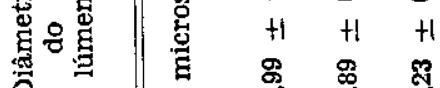
密热

㞼

Q

突

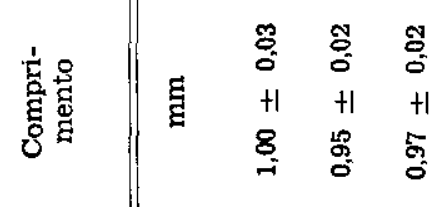

ॐ

兽 $+1 \quad+1+$

占 站

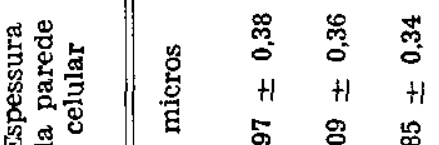

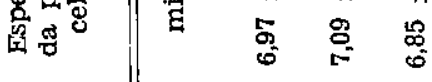

엻

密

总。总

悤 今.

总 $+1 \quad+1$

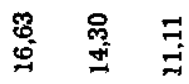

宽

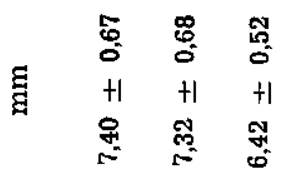

宛串 
Vol. 40 , Art. n. ${ }^{\circ} 11$


Figura 3. - Fotomicrografias das fibras de mamona (cultivar Guarani) : a, b, c - fibras lenhosas; d, e, f - fibras liberianas (1, 2 e 3: aumentos relativos de 40,100 e 400 vezes). 

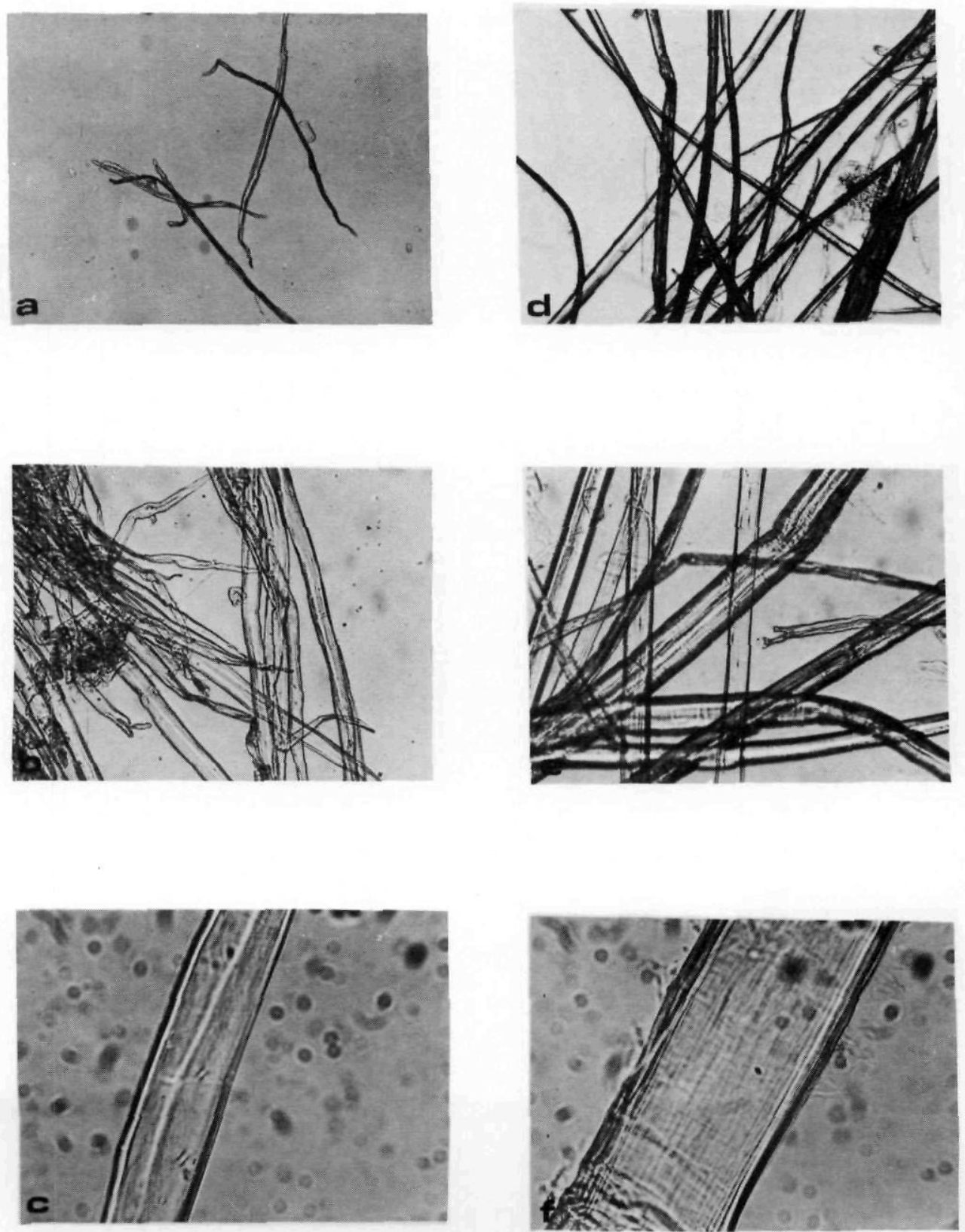

Figura 4. - Fotomicrografias das fibras da mamona (cultivar Borracha): a, b. c - fibras lenhosas; d, e. f - fibras liberianas (1, 2 e 3 : aumentos relativos de 40,100 e 400 vezes). 
Vol. 40 , Art. n. ${ }^{\circ} 11$
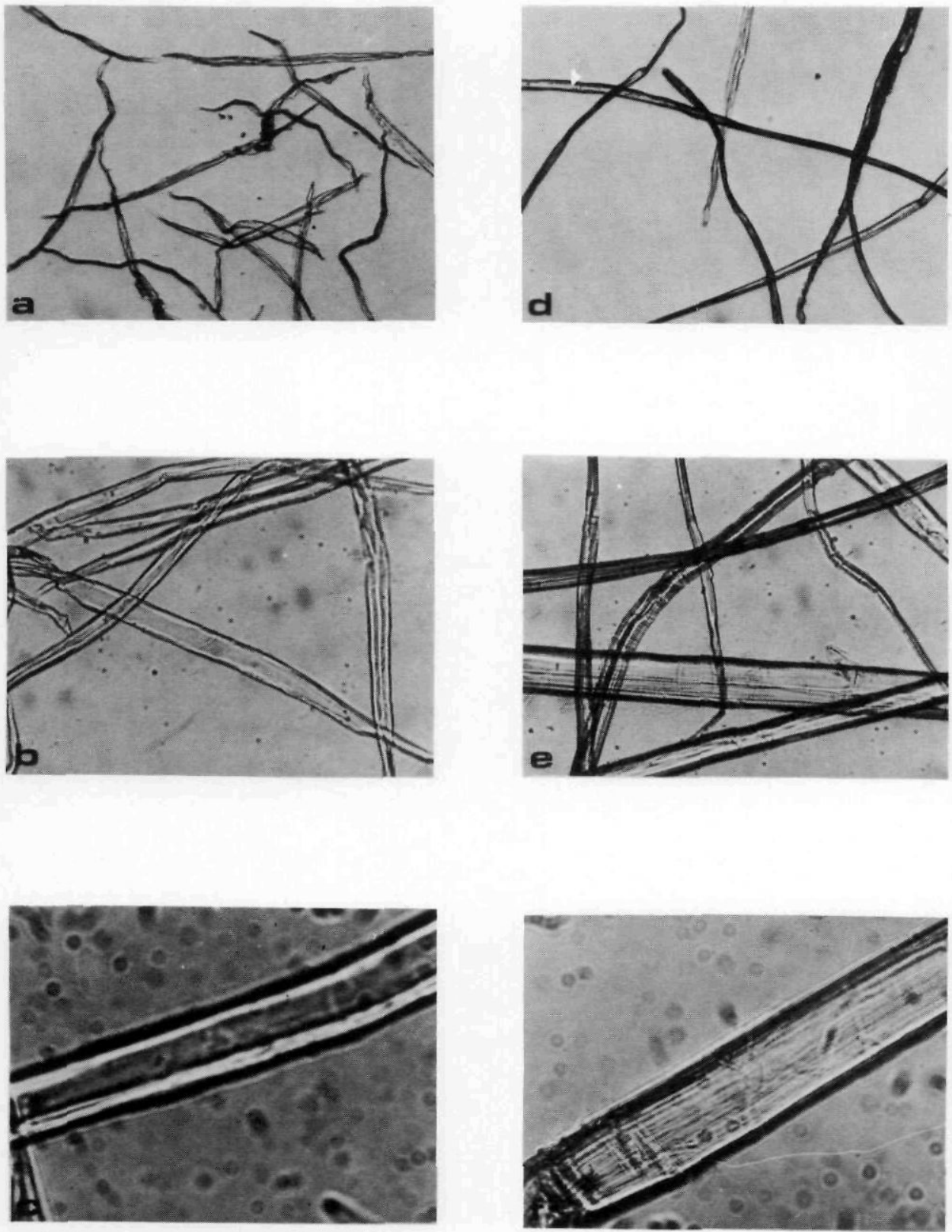

Figura 5. - Fotomicrografias das fibras de mamona (cultivar Preta) : a, b, c - fibras lenhosas; d, c, f - fibras liberianas (1, 2 e 3 : aumentos relativos de 40,100 e 400 vezes). 
As principais relações entre as dimensões das fibras (quadro 4), mostram que as fibras lenhosas de mamona, em relação às de eucalipto, apresentaram menores valores para as frações-parede e índices de Runkel e maiores valores para os coeficientes de flexibilidade. Essas relações indicam que as fibras de mamona são flexíveis, favorecendo suas interligações na formação do papel.

QUADRO 4 - Principais relações entre as dimensões das fibras liberianas e lenhosas em três cultivares de mamona

\begin{tabular}{|c|c|c|c|c|c|c|c|c|}
\hline \multirow[t]{2}{*}{ Cultivar } & \multicolumn{2}{|c|}{$\begin{array}{l}\text { Coeficiente de } \\
\text { flexibilidade }\end{array}$} & \multicolumn{2}{|c|}{ Fração-parede } & \multicolumn{2}{|c|}{$\begin{array}{c}\text { Indice de } \\
\text { enfeltramento }\end{array}$} & \multicolumn{2}{|c|}{$\begin{array}{l}\text { Indice de } \\
\text { Runkel }\end{array}$} \\
\hline & líber & lenho & líber & lenho & liber & lenho & liber & lenho \\
\hline & $\%$ & $\%$ & $\%$ & $\%$ & & & & \\
\hline Guarani & 54 & 67 & 46 & 33 & 242 & 35 & 0.8 & 0.5 \\
\hline Borracha & 50 & 70 & 50 & 30 & 257 & 35 & 1,0 & 0,4 \\
\hline Preta & 45 & 63 & 55 & 37 & 259 & 38 & 1,2 & 0.6 \\
\hline
\end{tabular}

\section{CONCLUSOES}

a) Nas condições específicas estudadas, a quantidade estimada de restos vegetais da cultura da mamona foi semelhante à produção do E. gran* dis plantado em solo de cerrado.

7:: As fibras liberianas e lenhosas ic caule de mamona, em comparaçāo com as fibras de pinus e eucalipto, podem ser consideradas, respectivamente, como longas e curtas.

c) O cultivar Guarani, com menor densidade básica do caule, apresentou maior porcentagem de líber.

d) A menor densidade do caule de mamona influi negativamente no rendimento do digestor, onde se processa a conversão em celulose.

e) O teor em celulose macerada não variou entre os cultivares de mamona estudados.

f) As fibras lenhosas de mamona são flexíveis e sugerem excelente interligação na formação da folha de papel.

\section{AGRICULTURAL RESIDUES OF CASTOR BEAN (RICINUS COMMUNIS L.) CROPS AS A RAW MATERIAL FOR PULP PRODUCTION}

\section{SUMMARY}

Agricultural residues of three cultivars of castor bean ('Guarani', 'Borracha' and 'Preta') were studied to produce pulp for paper manufacture.

The results showed that castor bean crops supplied a great quantity of fibrous agricultural residues. These residues have a low basic density and good macerated yield. Regarding Pinus sp. and Eucaliptus sp. fibers, the bast and woody fibers of castor bean can be reported, respectively, as long and short fibers. 
Vol. 40, Art. n. ${ }^{\circ} 11$

\section{FEFERÊNCIAS BIBLIOGRAFICAS}

1. ASSOCIAÇÃO TECNICA BRASIIJEIRA DE CELULOSE E PAPEL. Normas de ensaio. São Paulo, 1970.

2. BANZATTO, N. V.; SAVY FILHO, A.; SICHMAN, W. Diagnóstico da cultura da mamoneira no Estado de Sāo Paulo. Campinas, CATI, 1978. 8p. (Documento técnico, 9)

3. BARRICHELO, L. E. G. \& BRITO, J. O. Potencialidade de espécies tropicais de eucalipto para produção de celulose sulfato branqueada. IPEF, Piracicaka, 13:9-37, 1976.

4. FOELKEL, C. E. B.; BARRIChELO, L. E. G.; AMARAL, A. C. B.; VALIE, C. F. do. Variaçōes das características da madeira e propriedades de celulose sulfato de Pinus oocarpa em função da idade do povoamento florestal. IPEF, Piracicaba, 10:81-87, 1975.

5. - - - MILANEZ, A. F. Estudo comparativo das madeiras de Eucaliptus saligna, E. paniculata, E. citriodora, E. maculata e E. teriticornis para produção de celulose sulfato. IPEF, Piracicaba, 10:17-37, 1975.

6. MELLO, H. A.; SIMOES, J. W.; FERREIRA, C. A.; BRASIL, U. M. Influência do espaçamento e idade de corte na produçăo de madeira de eucalipto em solo de cerrado. IPEF, Piracicaba, 13:143-161, 1976.

7. NIESCHLAG, H. J.; NELSON, G. H.; WOLFF, I. A.; PERDUE JR., R. F. A search for a new fiber crops. TAPPI, 43:193-201, 1960. 